\title{
APPLICATION OF REAL-TIME SIMULATION TO ASSIGN DUE DATES ON LOGISTIC-MANUFACTURING NETWORKS
}

\author{
Alex J. Ruiz-Torres \\ Kazuo Nakatani \\ Computer Information Systems and Decision Sciences \\ College of Business \\ Florida Gulf Coast University \\ Fort Myers FL, 33965, U.S.A.
}

\begin{abstract}
This paper presents the application of real-time simulation to assign due dates on logistic-manufacturing networks. Information from the manufacturing, transportation, and supplier elements was integrated into a simulation model of the system to help the assignment of reliable delivery dates. In addition, the system was used to generate multiple due date options so customers could pick the delivery speed and cost option that satisfied their specific needs.
\end{abstract}

\section{INTRODUCTION}

This paper presents part of an investigation in the use of information technology (IT) and simulation to set order due dates in logistic-manufacturing networks. The combination of IT and simulation for decision making is often called real-time simulation. The first objective of the presented application of real-time simulation was to provide a method by which due dates can be set to achieve reliable deliveries for logistic-manufacturing networks. The second objective of the application was to generate alternative due dates, where each of these due date options had an associated price (premium price for faster delivery). This is a concept extensively used by the delivery service companies like UPS and Federal Express.

Due date/ price options are generated by simulating a new order through the logistic-manufacturing network with different production priorities and by considering different modes of transportation. When a customer places an order, operational data is updated via telecommunication technology: operational data includes current status of the logistic-manufacturing network, i.e. the level of raw material inventories, orders being processed and waiting, planned machine repairs, breakdown performance, carrier schedules, and other constraining elements of the network. After the model data is up-dated, the simulation is run with several preset scenarios in order to establish due date options with different prices. The data required to run and update this due date system is available in a growing number of manufacturing organizations, and can be obtained through internally networked information systems (i.e. manufacturing information and inventory systems) and by externally networking with suppliers and carriers.

This paper is divided as follows. We first present previous work in the area of simulation and real-time control and in the area of due date assignment. Second we describe a general framework that combines IT with simulation for real-time due date decision-making in logistic-manufacturing networks. Third we describe the development and implementation of a simulation-based due date system to a small manufacturer of make-to-order products. Finally we present a summary and propose additional work in the area.

\section{BACKGROUND}

Simulation has been used for logistic planning and decision making for more than twenty years (Ballou 1992). Simulation continues to gain additional capabilities and has a growing role as a tool for real-time control (Harmonosky 1990, Rohrer 1997). Real-time control through simulation the use of a simulation model to aid in making an immediate decision- has been proposed for a number of settings, especially for manufacturing systems applications (McConnell and Medeiros 1992, Rogers and Gordon 1993). The use of simulation for real-time control has been made possible largely because of the introduction of computers to the factory floor and the advances in informatica (McConnell and Medeiros 1992).

Information systems have also gained great importance, and are now an integral part of many logistic systems. The global nature of logistics requires information systems that result in enhanced inventory control, order 


\section{Ruiz-Torres and Nakatani}

and material tracking, and efficient resource utilization (Lewis and Talalayesvsky 1997). These information systems need to also take into consideration that material moves across national boundaries, in multiple currencies, and that getting to its destination on time is critical to customer satisfaction (Hameri and Paatela 1995). Recent surveys indicate that the trend to implement information systems, like EDI, will continue, as for example, in the area of motor carriers (Murphy and Daley 1996).

The continued implementation of sophisticated information systems provides the foundation for applications of real-time control through simulation. Realtime simulation is based on the ability of the system to obtain the real-time data needed to update the simulation model. Many manufacturing systems have had this capability for many years - a primary reason for the large number of real-time control with simulation applications in this area. In essence, simulation-based real-time control uses a simulation model initialized to the system's current status and a number of 'what-if' scenarios runs of the model to aid in making an immediate decision (McConnell and Medeiros 1992).

The immediate decision of concern in this project is the assignment of due dates to customer orders. Assigning due dates is widely recognized as very important given its customer service implications (Cheng and Gupta 1989). Due date assignment is a difficult problem given the dynamic nature of most manufacturing and logistic environments. In many MRP environments, due dates are based on the estimated flowtime of an order plus some slack (Fry, Philipoom, and Markland 1989). Several due date assignment methods have been proposed including (Chang 1996): Constant Flow (CON): $\mathrm{d}_{\mathrm{i}}=\mathrm{r}_{\mathrm{i}}+k$; Equal Slack (SLK): $\mathrm{d}_{\mathrm{i}}=\mathrm{r}_{\mathrm{i}}+\mathrm{p}_{\mathrm{i}}+k$; Number of operations (NOP): $\mathrm{d}_{\mathrm{i}}=\mathrm{r}_{\mathrm{i}}+k \mathrm{n}_{\mathrm{i}}$; Total Work $(\mathrm{TWK}): \mathrm{d}_{\mathrm{i}}=\mathrm{r}_{\mathrm{i}}+k \mathrm{p}_{\mathrm{i}}$; Jobs in System (JIS): $d_{i}=r_{i}+p_{i}+k J_{i} ;$ where $d_{i}, r_{i}, p_{i}, n_{i}$, and $J_{i}$, denote the due date, the arrival time, the processing time, the number of operations, and the number of jobs in the system of the job's routing when job i arrives. The value of $k$ relates to the amount of slack time added to the due date.

\section{DYNAMIC DUE DATE ASSIGNEMNT ON LOGISTIC-MANUFACTURING NETWORKS}

In this paper we propose a due date assignment method where the information from the manufacturing centers, the transportation services, and the raw material suppliers (the logistic-manufacturing network) is utilized in order to increase the accuracy of the due date forecast. During the remaining of the paper we will refer to the logisticmanufacturing network being modeled as the system.

The information about the current status of the system is used to maintain the simulation model 'up-to-date'. The required functionalities and operations of the SimulationBased Due Date Estimator System (SDDES) are summarized in Figure 1. Inputs and outputs of the SDDES and its associated external elements are illustrated in Figure 2. The process starts when a customer requests a price and delivery quote for one or more custom made items and this information is entered into the SDDES (1). The SDDES obtains current system information through internal networks (i.e. LAN) and external networks (i.e. EDI) to update its records on resources, inventories, etc (2). The SDSS executes simulations of the new order under several pre-set scenarios (i.e. rush order) to generate price/due date options (3). The price/due date options are offered to the customer (4) and the customer makes a decision (5). The customer's decision is forwarded as routing/scheduling/material flow instructions to the corresponding logistic-manufacturing resources and to the information systems (6).

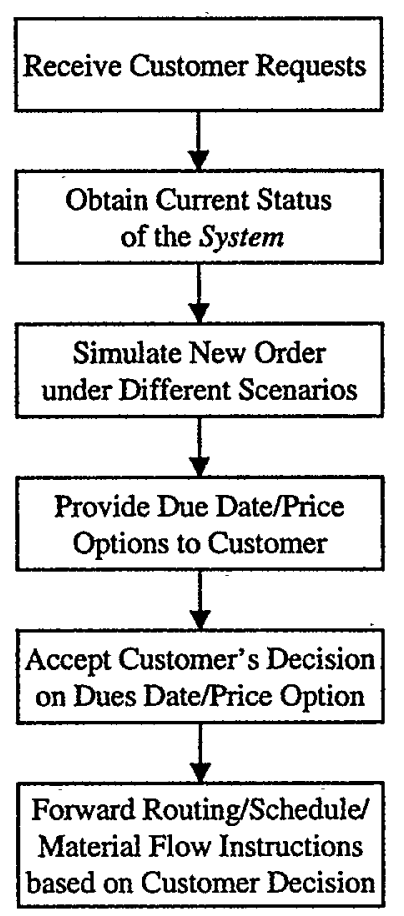

Figure 1: Required Functionalities and Operation of SDDES 


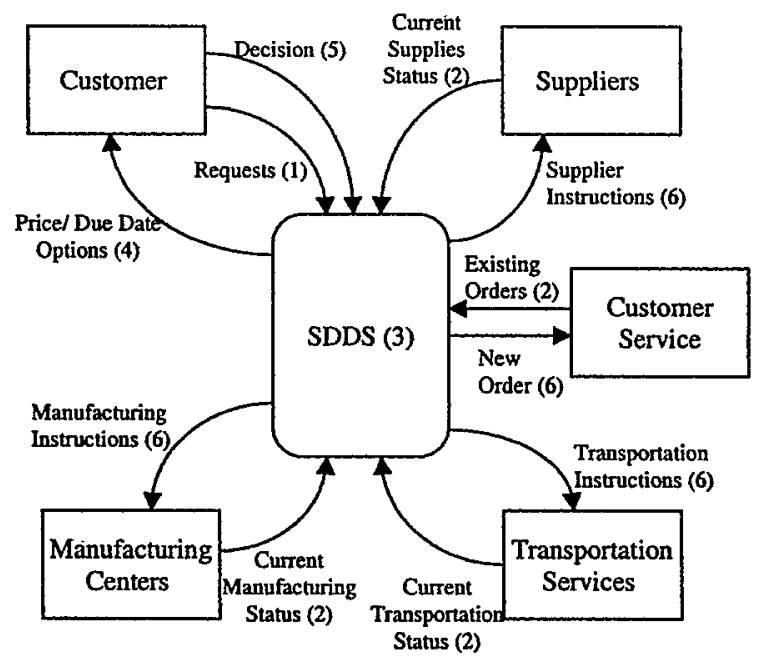

Figure 2: Inputs and Outputs of SDDES and its External Elements

\subsection{SDDES Data Requirements}

The data required by the system includes a list of orders pending and information on all of the elements of the logistic-manufacturing network. As in Rogers and Gordon (1993), information is both 'static' (e.g. products, processes, and resource capabilities) and 'dynamic' (e.g. shop floor status, inventories, carrier schedules, carrier space), and must be available for the due dates to be valid. Status information is required from all the manufacturing centers required by the product ordered, and for all the possible combinations of transportation services between all the required manufacturing centers.

\subsection{SDDES Implementation Issues}

Rogers and Gordon (1993) and Harmonosky (1990) describe the basics elements required for a successful application of real-time simulation to schedule and control manufacturing systems. Most of these issues still apply when the concept is expanded to logistic-manufacturing networks. Two implementation issues of special relevance to the due date assignment and management process are the (1) the size of slack time $(k)$ to be included in the due date assignment equation and (2) the number of replications to be run under each scenario. In relation to the first question, even when tight due dates are desired, some slack time needs to be included for two reasons. The first reason is that most complex systems face unexpected disruptions and variation, and some slack serves as a 'protective' buffer. The second is that without some slack, the system has no flexibility that allows new orders to be expedited through the system. If all due dates are very tight, then adding a rush order may make one or more of the orders already in the system late. The due date for an order is then described by: $d_{i}=r_{i}+E\left(C_{i}\right)+k$, where $E\left(C_{i}\right)$ is the expected time required for completing that order (job).

The determination of $E\left(C_{i}\right)$ goes back to the second question, how many replications to run. Several replications are required in order to account for system variability, thus obtaining a better estimate of the expected completion time. The number of runs will depend on the time available to generate price/due date options; how long customers are willing to wait on the phone for a price/delivery quote, and the system's inherent variability. We believe that as the system is validated, a fixed number of replications should be pre-set which provide a reasonable tradeoff between the time to estimate $E\left(C_{i}\right)$ and the confidence interval of this value. Further information on analyzing simulation results can be found in Law and Kelton (1991).

\subsection{SDDES Scenarios}

One of the most important benefits of the SDDES is its ability to generate price/due date options through experimentation with pre-set scenarios. The number of scenarios to be tested will again depend on the time customers are willing to wait for the quote, previous experience with customers preferences, and the flexibility of the system. First, each scenario will add time to the run time of the SDDES, second, some scenarios may exist (i.e. transporting concrete slabs via air freight) which will never make sense, and third, the system may have only a few options that can be modified (i.e. single supplier).

The pre-set scenarios will consist of variations to the routing and priority assigned to the order. The change of routing and priority results in changes to the price and due date of the order. An order that is expedited through the system will cost more given the additional resources required (i.e. additional machine set-up) and/or external costs (i.e. difference between rail and air freight). Some examples of pre-set scenarios are:

- High priority on all manufacturing centers.

- Regular priority on all manufacturing centers.

- Fast transportation modes in all material flows.

- Slow transportation modes in all material flows.

- Selection of high cost/short lead time supplier.

- Selection of low cost/high lead time supplier.

Each of these scenarios results in a price and due date based on the status of the system and on the new order's specifications. For example, if the new order is expedited through all the manufacturing centers (high priority) and 
uses all the fast modes of transportation, its due date may be in one week from ordering point and at an additional price of $10 \%$. If the new order is processed in the standard plan (manufacturing and transportation), then the due date may be two and a half weeks from the ordering date and at the regular price. Additional options include expediting only at the factory floor, but using the regular modes of transportation.

\section{APPLICATION OF THE SDDES}

An SDDES prototype was implemented on a local manufacturer of make-to-order safety glass. The company was started only a year ago and has grown in one year from a garage operation to one hiring more than 100 employees and 3 million in sales. This growth is expected to continue as they hold several patents on impact (bullet proof) and fire resistant glass of unique characteristics. The company is divided in four locations, three manufacturing plants, and one office location. All facilities are within a 50-mile radius.

The company produces several types of safety glass, each with relatively similar processes. Variations come in the way of raw materials and the number of layers. All orders are made to size - not in large sheets and then cut to required size as expected. The process is highly labor intensive and has a revolving flow where stages are visited two or more times during the process. Given the manual processes, production times are fairly variable. In addition, the yield for the processes also fluctuates and depends on several factors including raw materials, and the weather (temperature and humidity).

A basic description of the production process is presented in Figure 3. Once an order has been released to the floor, glass is cut to the specified size and cleaned. Each piece of glass is then prepared to hold a layer of resin or glue, and then film or glass is attached like a 'sandwich'. The glass then goes to a curing stage for eight or more hours. After curing, the glass goes back to preparation, and then to receive another layer of glue and film. This process is repeated several times depending on the type of glass and customer specifications. The glass is continuously inspected for lint, particles, and bubbles. After the last layer is added and curing completed, the product is inspected, cleaned and packed. The packaged glasses are shipped through several carriers to customers across the United States.

\subsection{Due Date Assignment Process}

Due dates for customer orders (quantities that ranged from less than ten to thousands of pieces of glass) were set based on a qualitative match between customer requirements and

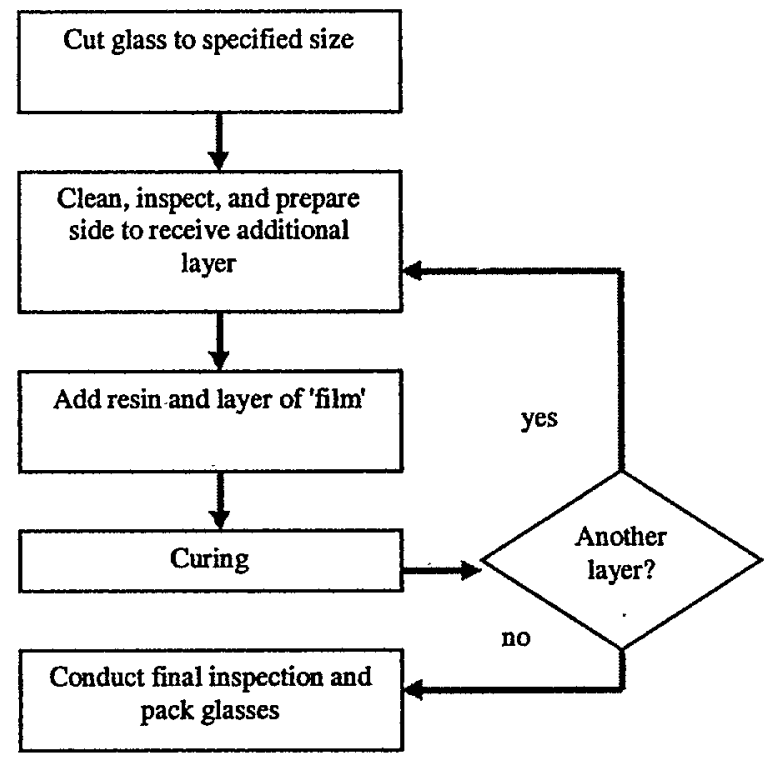

Figure 3: Flow of the simulated process.

the perceived load on the system by the sales personnel. This due date method was effective in most cases - about 95\% on-time delivery. The effectiveness of the method was attributed to the relatively small size of the operation and the high lead times given to customers. However, the increase of demand and associated complexity of the operation were making it harder to determine due dates that would be acceptable to customers and could be met on time.

The due date assignment process was complicated by the possibility of order splitting for large orders and by costs associated with late orders. Large orders were often divided into multiple partial orders, each with its own due date. This was done as a way to balance the load of the production system. Late orders had a high backorder costs because most of the company's clients are in the construction business, an industry where penalties for not completing a task (delivering materials) at a specified time often results in daily fines.

\subsection{Modeled Elements}

The SDDES prototype for this company was developed with Boreland's Delphi 3 application development tool. The model includes the manufacturing and logistic factors that resulted in a valid representation of the network. The validity of the model was tested by utilizing real input data and comparing the model's output to the historic results. The manufacturing factors included in the model were processing lead times and variation, yield, set-up times, and capacity (labor, machines, storage). The logistic factors included in the model were the inventory level and 
scheduled delivery for the four primary raw materials, and the pickup schedule for the utilized shipping services.

\subsection{System Operation and Scenarios}

The input data files were updated once per day given it required reading files sent through e-mails (the facilities are not in a network). This is an example of a compromise over the ideal configuration for the SDDES presented in Section 3. As the system data is not updated during the day (current), new orders were only considered for release after the current day.

When a customer called to get a quote on a new order, a member of the sales group entered the new order data into the SDDES prototype. The information for the order included the type of glass (including the layers and materials), the sizes $\left(\mathrm{H}^{\prime} \times \mathrm{W}^{\prime}\right)$, and the quantity for each size and type. Once this was entered, the SDDES read four input data files: raw material inventories and delivery dates, shipping pickup schedules, orders not released, and orders in WIP. These files had up-to-date information on inventory levels, transportation options and schedules, orders waiting to be processed, and work-in-process glass.

The scenario manager had three 'simple' scenarios: placing the order at the end of the list of high priority orders; at the end of the list of normal priority items, and at the end of the complete order list (low priority). The simulation run ten replications of each scenario in order to estimate the completion time of all the items on the order, and then gave the user three price/due dates that were based on the investigated priorities. The system utilized a slack time which depended on the order's priority but that could be modified by the user. The SDDES prototype contained a price model that determined how much each glass should cost under each scenario. Finally, if under any of the scenarios the new order made one of the existing orders late, that price/due date option was not offered to the customer. Large orders were often divided (agreement of quantities between the customer and sales) and a set of due date options was determined for each partial order.

\subsection{Unresolved Issues}

One important issue that is currently unresolved by the current prototype of the SDDES system is determining release dates in cases where the customer has a predetermined due date in mind. This case, often called backwards scheduling, requires figuring out when the order must be started (release time) given a specified finish time (the selected due date) -versus determining when it will be finished given a specified start time. One alternative is to finish the order well in advance and either ship it before its due date, or store it in-house until its due date. The first option is unacceptable to many customers, as they will be incurring in additional costs (i.e. storage). The second option results in higher holding, storage, and handling costs for the manufacturer. The solution is then to use simulation to determine the release date that allows production and shipment to be completed before the due date, but with little deviation from it. Recent work in the area by Watson et al. (1997) that evaluates backward scheduling for Make-To-Order systems will help the future addition of this feature to the SDDES.

\subsection{System Performance}

Users have provided very favorable feedback about the effectiveness of the prototype and want its extension into order tracking and resource optimization. The current prototype has helped the company reduce the average quoted lead times while still - maintaining high levels of delivery performance.

\section{CONCLUSIONS}

This paper presented the application of real-time simulation into the arena of logistic-manufacturing and customer service (due date assignment). This paper showed that by combining the IT capabilities of logisticmanufacturing networks with a simulation model, a tool can be developed which can simultaneously:

- assign tight due dates,

- maintain or increase the level of on-time deliveries,

- generate options on due dates based on routings/priority and transportation service options.

Major implementation problems can limit the success of real-time simulation. The first is the feasibility of linking production, inventory, transportation, and other information systems to the simulation model. Production information is internal, therefore accessible -not necessarily automatically-, but external information (e.g. transportation carriers status) may be harder to obtain, integrate, and of questionable reliability. Another problem area is the effect of expediting some orders, as the simulation model may show that doing this will delay some current orders beyond their due date. If the simulation model shows that expediting a new order makes an existing order late, should the alternative be presented to the customer?

We believe that the implementation of the simulationbased due date assignment methodology in logisticmanufacturing networks will result in two major benefits. First, the delivery performance will improve dramatically as due dates are based on a completion forecast that derives 
from real-time information about resources, queues, schedules, and the systems variability. Second, in cases where delivery performance is not a problem, the simulation-based approach will provide due date options (e.g. priority orders at a premium price). Future work on the project includes addressing the backward scheduling issue and the extension of the prototype to other control and management areas such as order tracking, resource management, and network optimization.

\section{REFERENCES}

Ballou, R. H. 1992. Business Logistics Management. New Jersey: Prentice Hall.

Chang, F. R. 1996. A study of due date assignment rules with constrained tightness in a dynamic job shop. Computers and Industrial Engineering 31-1/2: 205208.

Cheng, T. C., and M. C. Gupta. 1989. Survey of scheduling research involving due date determination decisions. European Journal of Operations Research 38: 156166.

Fry, T. D., P. R. Philipoom, and R. E. Markland. 1989. Due date assignment in a multistage job shop. IIE Transactions 21-2: 153-161.

Hameri, A., and A. Paatela. 1995. Multidimensional simulation as a tool for strategic logistics planning. Computers in Industry 27: 273-285.

Harmonosky C. M. 1990. Implementation issues using simulation for real-time scheduling, control, and monitoring. Proceeding of the 1990 Winter Simulation Conference, ed. O. Balci, R. P. Sadowski, R. E. Nance: 595-599.

Law, A. M., and W. D. Kelton. 1991. Simulation Modeling and Analysis. New York. McGraw Hill.

Lewis, I. and A. Talalayevsky. 1997. Logistics and Information Technology: A Coordination Perspective. Journal of Business Logistics. 18-1: 141-157

McConnell, P. G., and D. J. Medeiros. 1992. Real-Time Simulation For Decision Support In Continuous Flow Manufacturing Systems. Proceeding of the 1992 Winter Simulation Conference, ed. J. J. Swain, D. Goldsman, R. C. Crain, and J. R. Wilson: 937-944.

Murphy, P.R. and J. M. Daley. 1996. International Freight Forwarder Perspectives on Electronic Data Interchange and Information Management Issues. Journal of Business Logistics. 17-1: 63-84.

Rogers, P., and R. J. Gordon. 1993. Simulation for realtime decision making in manufacturing systems. Proceeding of the 1993 Winter Simulation Conference, ed. G. W. Evans, M. Mollaghasemi, E. C. Biles: 866874.
Rohrer, M. 1997. Seeing is believing: The importance of Visualization in Manufacturing Simulation. IIE Solutions 29-5: 24-28.

Watson, E. F., D. J. Medeiros, and R. P. Sadowski. 1997. A Simulation-Based Backward Planning Approach for Order-Release. Proceeding of the 1997 Winter Simulation Conference, ed. S. Andradottir, K. J. Healy, D. H. Withers, and B. L. Nelson: 765-772.

\section{AUTHOR BIOGRAPHIES}

ALEX J. RUIZ-TORRES is an assistant professor in the Department of Computer Information Systems and Decision Sciences at Florida Gulf Coast University. His research interests include systems simulation, supply chain management, production scheduling, and manufacturing systems. He received a BIE degree from Georgia Tech, an MSIE from Stanford University, and a Ph.D. from Penn State University. $\mathrm{He}$ is a member of INFORMS, IIE, ASEE, and POMS.

KAZUO NAKATANI is an assistant professor of Computer Information Systems at Florida Gulf Coast University. $\mathrm{He}$ is a Ph.D. Candidate in Management Information Systems at Texas Tech University. His current research interests include systems analysis and design, application of information technology in logistics and production systems, and Business Process Reengineering. 